\title{
Applying the Collaborative Approaches to Evaluation (CAE) Principles in an Educational Evaluation: Reflections from the Field
}

\author{
Jeremy Acree \\ University of North Carolina at Greensboro
}

\begin{abstract}
This practice note presents reflections on the application of the collaborative approaches to evaluation (CAE) principles used as a guide in planning, implementing, and managing a collaborative evaluation in a higher educational setting. The reflection is based the evaluation of a technology integration program intended to enhance K-12 teacher preparation in a school of education at a public university in the southeast United States. The evaluation was conducted during a one-year period by the author and a diverse team of novice and experienced evaluators. Discussion of the principles and their influence on collaborative practice are based on an analysis of evaluator reflections, meetings with stakeholders, and a culminating interview with stakeholders that were recorded and documented throughout the evaluation. Key takeaways from our reflection and analysis highlight the ways in which the CAE principles encourage reflection, the emphasis of some principles based on the specificities of context, and challenges applying the principles that emerged throughout the evaluation.
\end{abstract}

Keywords: CAE principles, collaborative evaluation, education, evaluation practice, reflective practice

Résumé : La présente note sur la pratique présente des réflexions sur l’application des principes visant à guider les approches collaboratives en évaluation (ACE) pour orienter la planification, la mise en œuvre et la gestion d'une évaluation collaborative dans un contexte d'enseignement supérieur. La réflexion est fondée sur l'évaluation d'un programme d'intégration de la technologie conçu pour la préparation des enseignantes et enseignants de la maternelle à la $12^{e}$ année, dans une faculté déducation d'une université publique du sud-est des États-Unis. Lévaluation a été réalisée pendant une période d'un an par l'auteur et par une équipe diversifiée d'évaluatrices et d'évaluateurs chevronné.e.s et débutant.e.s. La discussion des principes et de leur influence sur la pratique collaborative découle d'une analyse des réflexions des évaluatrices et évaluateurs, de rencontres avec des intervenant.e.s et d'une entrevue finale avec les intervenant.e.s, qui ont été enregistrées et consignées tout au long de l'évaluation. Les principales conclusions tirées de notre réflexion et de notre analyse

Corresponding author: Jeremy Acree, University of North Carolina at Greensboro, 1300

Spring Garden St, Greensboro, NC 27412, USA; jgacree@uncg.edu

(c) 2019 Canadian Journal of Program Evaluation / La Revue canadienne d'évaluation de programme 34.2 (Fall / automne), 272-281 doi: 10.3138/cjpe.53185 
portent sur les façons dont les ACE encouragent la réflexion; l'accent mis sur certains principes selon le contexte; et les défis liés à l'application des principes qui ont été notés pendant l'évaluation.

Mots clé : principes d'ACE, évaluation collaborative, éducation, pratiques d'évaluation, pratique réfléchie

Collaborating with stakeholders in the planning and implementation of evaluation involves navigating and managing expectations, communication, and relationships (King, 2005). These uncertain dimensions of practice require that evaluators not only draw from theoretical knowledge but also conduct what Schon (1983) refers to as "reflection-in-action" in order to make thoughtful decisions based on experience, inclinations, and predispositions (Chouinard et al., 2017). Designing and conducting collaborative evaluation thus requires flexibility in methods, models, and techniques (Cousins, Whitmore, \& Shulha, 2013). Acknowledging the inherent contingencies in this type of approach, Shulha, Whitmore, Cousins, Gilbert, and al Hudib (2016) developed the collaborative approaches to evaluation (CAE) principles to offer empirically derived practical guidance while allowing space for evaluators to respond to the specificities of context. As Shulha et al. explain, the principles offer a "system for thinking about collaborative approaches to evaluation (CAE) ... intended to support considerations of professional practice, both generally and in situ" (p. 193).

The CAE principles are a product of extensive empirical analysis and synthesis. Through a sequence of both in-depth and broad studies, the perspectives and experiences of more than 300 practicing evaluators were distilled into eight interconnected principles, revealing a comprehensive depiction of collaborative approaches in practice (Shulha et al., 2016). Despite the substantial time and effort spent in their development, Shulha et al. (2016) assert that the principles should be viewed as fluid and subject to ongoing revision. They suggest that the utility of the principles will be clarified and refined through further empirical study as evaluators reflect upon and analyze their application in practice.

In this practice note, I reflect on the experience of working with the CAE principles as a guide in planning, implementing, and managing a year-long collaborative inquiry in a higher education setting. This analysis connects directly to two of the four suggestions provided by Shulha et al. (2016) for integrating the principles into evaluation practice and scholarship: (1) applying the principles as "a guide to planning and implementing CAE", and (2) using the principles as "a basis for retrospective reflection on completed projects (with an eye to surfacing lessons learned)" (p. 212). I used the following questions to guide my analysis of the CAE principles:

- In what ways and to what extent do the principles influence and guide practice throughout the evaluation process?

- In what ways are the principles useful to novice evaluators? 
To address these questions, I analyzed evaluator reflections, meetings with stakeholders, and a culminating interview with stakeholders. The practice note begins with an overview of collaborative approaches to evaluation and the CAE principles, followed by a description of the context of the evaluation. It concludes with a discussion of lessons learned regarding collaborative approaches to evaluation and the utility of the principles to guide practice.

\section{COLLABORATIVE APPROACHES TO EVALUATION}

The CAE principles are not defined by a singular technique or method but refer to a family of approaches which call for a partnership to conduct systematic inquiry between evaluators who understand evaluation processes and methods and those communities, individuals, or groups with knowledge of the program and community context (Cousins \& Chouinard, 2012). Numerous authors (see Cornwall \& Jewkes, 1995; Cousins \& Chouinard, 2012; Cousins et al., 2013) have provided lists of approaches that fit under the collaborative umbrella, including participatory (e.g., Cousins \& Whitmore, 1998; King, 2005), transformative (e.g., Cousins \& Whitmore, 1998; Mertens, 2009), empowerment (Fetterman, 2001), collaborative (O'Sullivan, 2004, 2012; Rodríguez-Campos, 2005, 2012), and developmental evaluation (Patton, 2011), among others. Throughout the literature, the term "collaborative" is used loosely and often interchangeably with "participatory," reflecting the broad nature of this categorization.

The CAE principles are heavily influenced by participatory research methods, such as participatory action research and rapid rural appraisal, which Cousins et al. $(2013$, p. 8$)$ suggest were "developed at least in part as a reaction to positivist models of inquiry that were seen as exploitive and detached from urgent social and economic problems." Collaborative approaches emphasize the importance of context and often rely on stakeholder involvement to generate findings that are relevant and useful for local problem solving (Cousins \& Whitmore, 1998). According to Cornwall and Jewkes (1995, p.1668), participatory methodologies draw attention to "who defines research problems and who generates, analyses, represents, owns and acts on the information which is sought." Participatory research goes beyond the inclusion of program participants as data sources, addressing issues of control over the research agenda and process.

Cousins and Chouinard (2012) specify three justifications for collaborative inquiry: pragmatic, political, and philosophical. Approaches based on a pragmatic justification are oriented toward problem solving, aiding organizational decision making, and facilitating the use of evaluation findings and processes (Cousins \& Whitmore, 1998). Politically motivated approaches focus on social action and transformation through the empowerment of individuals and groups, particularly those who have been historically marginalized (Cousins \& Whitmore, 1998). Although these two streams of participatory evaluation differ in their primary emphasis, they share a philosophical justification in that they aim to produce deeper, more meaningful knowledge through collaboration (Cousins et al., 2013). 
Empirical studies have found that collaborative approaches to evaluation can increase the utilization of evaluation findings and processes and can promote individual and organizational learning (Cousins \& Chouinard, 2012). By taking an educative role, evaluators can foster intra-organizational dialogue and a culture of evaluative thinking (Cousins \& Earl, 1992). However, these instrumental and conceptual benefits are not without limitations. Cornwall and Jewkes (1995) highlight the complexity of participatory methods and the challenges that can arise from unintended consequences, conflicting agendas within communities, and practical limitations of time and resources. Stakeholder needs, predispositions, and levels of commitment to evaluation influence the degree to which evaluation can achieve political and pragmatic goals (Cousins et al., 2013).

\section{THE CAE PRINCIPLES}

The CAE principles serve as a pragmatic tool for navigating the partnership between evaluators and program and community stakeholders across unique and complex contexts (Shulha et al., 2016). The authors of the principles do not specify how they are to be applied in practice, but they do provide two considerations regarding their utility. First, they suggest that each principle is essential, and implementation of each is a matter of degree, not a "whether-or-not" decision. Second, they assert that the principles carry only a "loose temporal order" and that certain principles should not be emphasized a priori. The eight principles are presented as follows:

- clarify motivation for collaboration,

- follow through to realize use,

- promote evaluative thinking,

- monitor evaluation progress and quality,

- monitor and respond to the resource availability,

- promote appropriate participatory processes,

- develop a shared understanding of the program, and

- foster meaningful relationships. (Shulha et al., 2016, p. 194)

Despite the recency of their publication, some research already exists on the use of the principles in practice. A forthcoming book, Global Test Drive of Principles for Collaborative Approaches to Evaluation (CAE), edited by J.B. Cousins, presents empirical studies of the application of the principles in practical and pedagogical settings (Cousins, forthcoming). In one chapter, Searle, Merchant, Chalas, and Lam (previously published in 2017) describe using the principles as a framework for examining how evaluation theory connects with practice. In a case study of a developmental evaluation, they found that the principles "allow the reflective evaluator to focus on the elements of collaboration, allowing her to better understand the challenges and success of the evaluation" (p. 368). In another chapter, Chouinard, Cavanaugh, Adetogun, and Baker (forthcoming) describe 
their application of the principles as a pedagogical tool, engaging students in dialogue and facilitating reflection on the purpose, methods, and consequences of collaborative practice. In the subsequent analysis, I present further evidence regarding the utility of the principles as a guide to practice and tool for reflection and learning.

\section{CONTEXT}

The Transforming Teaching through Technology (T4) program is a wide-ranging initiative supporting the School of Education at a public university in the southeast United States and its partnership with seven K-12 schools in two nearby districts. The project is focused on integrating emerging technologies into the institution's teacher preparation program curriculum and local classroom instruction by providing monetary incentives, technology resources, and support staff. Components of T4 include hands-on learning studios known as "makerspaces" at the university and seven partner schools, summer professional development camps for K-12 teachers, and working groups of university faculty focused on technology integration in teacher preparation courses. At the time of the evaluation examined here, the program was in its fourth year of a five-year grant cycle. Evaluations in the first three years focused on development and improvement of individual program components.

The evaluation team consisted of three graduate students (including the author), a faculty advisor, and an external evaluator. We applied a mixed method design to capture both impact and sustainability data from multiple sources, including faculty, pre-service students, grant support staff, and program documentation. The primary mode of collaboration was formal meetings with a stakeholder group assembled by the evaluation team with assistance from T4's principal investigator. The group comprised partner-school liaisons, universitybased program staff, and faculty with close ties to the program.

While we would have preferred a more collaborative approach with our stakeholder group, due to their busy schedules we were able to collaborate with them only during specific points in the evaluation. We held three formal meetings, one each during the design phase of the evaluation, prior to data collection, and after an initial round of data analysis. Each meeting was roughly three hours in length and structured around sharing updates on the evaluation with stakeholders, facilitating dialogue on future directions, and providing a forum for stakeholder input, questions, suggestions, and clarifications. When stakeholders could not attend formal meetings, we followed up with individual conversations over the phone, through email, or in person.

\section{PRACTICAL SIGNIFICANCE AND LESSONS LEARNED}

To explore and test the utility of the CAE principles, we selected specific points during the planning, implementation, and reporting of the evaluation to review 
the principles, question our understanding of them, and reflect on the extent to which certain principles influenced our practice. In our discussions, the evaluation team engaged in what Buckley, Archibald, Hargraves, and Trochim (2015) call "evaluative thinking," critically reflecting on the meaning and relevance of the principles in our collaborative work. Through this dialogue, we surfaced differing perspectives and experiences, examined individual and collective assumptions, and converged on points of consensus (Chouinard et al., forthcoming).

In this practice note, my analysis of the influence and utility of the CAE principles was based on documentation of evaluation team meetings, reflective discussions, and stakeholder group meetings through note taking and audio recordings, which were then selectively transcribed. A brief group interview with stakeholders at the end of the evaluation was also audio recorded and transcribed. Those documents served as the primary data sources for the key takeaways presented below, although informal conversations with evaluation team members have also shaped some of the findings and discussion. The opportunities, benefits, and challenges that emerged from our analysis are discussed below.

\section{Principled Reflection}

Using the CAE principles as a guide led us to critically reflect throughout the evaluation on the methods and complexities of collaborative inquiry. A consistent tension between the flexible nature of the principles and the situational demands of practice stimulated dialogue among the evaluation team regarding which principles to emphasize, when, and in what ways. Shulha et al. (2016) intentionally avoid prescriptive direction, and that ambiguity turned our application of the principles into an ongoing, negotiated process among the evaluation team. How can we best foster meaningful relationships with stakeholders? How do we promote evaluative thinking and what does it look like when it occurs? Is our evaluation likely to be used? Questions such as these were raised around many of the principles as we deliberated on the evaluation approach and methods.

Reflection was particularly beneficial for the team's three novice evaluators, who had no prior experience conducting collaborative evaluation. As noted by one evaluator in a team meeting, "this discussion [of principles] helps us to identify areas where we need further clarification regarding our evaluation plan and about the program." Taking the time to discuss how the principles applied to specific methods and decisions clarified expectations for collaboration and led to thoughtful and intentional discussions with stakeholders. For example, reflections after our first meeting with stakeholders generated a list of discussion topics for our second meeting, focused on revising initial plans as well as outlining specific next steps. The nature of the principles encourages-and perhaps requires-reflection if they are to be applied meaningfully in practice. For us, that reflection ultimately led to deeper understanding of collaborative inquiry and practical insights into the program and our approach to the evaluation. 


\section{Prioritization of Principles}

Over the course of the evaluation, some principles received more consideration than others. Although we sought to map our practice at different points onto each of the principles, the broad scope and compartmentalized nature of T4 led us to focus our dialogue extensively on three principles: clarifying motivation for collaboration, developing a shared understanding of the program, and following through to realize use.

We initially expected that clarifying motivation for collaboration would be a product of conversations with stakeholders during the early stages of the evaluation, laying the foundation for the remainder of our work together. Instead, this principle was relevant throughout the evaluation and was a topic of discussion from the design phase until after our final report was sent to the project director. Articulating the purpose of collaborative evaluation and establishing expectations with stakeholders was an ongoing process. A presentation on CAE in our first meeting with stakeholders initiated dialogue, but interviews at the end of the evaluation indicated that some uncertainty was never fully resolved. One stakeholder felt he contributed to the evaluation, saying, "I was on the ground, dealing with the teachers and students in the schools, so I thought I was able to provide some insight in that arena." Others, though, felt that meaningful collaboration was limited. One stakeholder said, "evaluators have come in over the years, watching us, but I don't feel like I have given much input into the evaluation." Shulha et al. (2016, p. 200) suggest that "not only is it important to establish the meaning of the CAE application early, there are also benefits to reinforcing this meaning over time." This was true for us, and additional discussion around the purpose of collaboration probably would have improved multiple aspects of the evaluation.

The organizational structure of T4 made developing a shared understanding of the program an important principle for our collaboration with stakeholders. University faculty, program staff, partner-school liaisons, and even some graduate students each have critical, but often isolated, roles in T4. Our stakeholder meetings brought representatives from these groups together, and discussions of how the various components of $\mathrm{T} 4 \mathrm{fit}$ together and worked toward a common aim was beneficial for both stakeholders and evaluators. As one stakeholder said early in the year, "I'd like to get an idea of what's happening in other places.... I just get a small view of it. I'm sure there's a lot more going on." Stakeholder perspectives also informed our decision to focus on program sustainability, and their input was a primary factor in defining the indicators we used to guide data collection and analysis. Shulha et al. (2016) emphasize responsiveness to context and stakeholder needs throughout their description of the principles, and a focus on local, situational demands is particularly evident in developing a shared understanding of the program. In the T4 evaluation, that emphasis pushed us to challenge our own comprehension of the program goals and activities and to integrate the perspectives of stakeholders to form a more comprehensive understanding.

In the first three years of the T4 program, it was difficult to identify examples of how our evaluations were being used in program decisions or used as a source 
of learning and program improvement. Those evaluations were intended primarily for the principal investigator and were included in federal reporting documents but were rarely a topic of program-level discussions. Therefore, one motivation for adopting a collaborative approach in the fourth year was a desire to increase both instrumental and conceptual uses of evaluation. By bringing together a diverse group of stakeholders, we could share the evaluation process and findings directly with individuals who could then incorporate the knowledge we built collectively into their own work. The CAE principles encouraged us to focus on practical outcomes of evaluation at the individual level, which Shulha et al. (2016, p. 210) describe as changes "in disposition toward the program or evaluation, and the development of program skills including systematic evaluative inquiry." By the end of our evaluation, stakeholders expressed enthusiasm for the knowledge we produced and a better understanding of the process and potential of evaluation. As one stakeholder said, "I am thinking now, is what I'm doing working? I guess that's what you're doing all the time [as evaluators], figuring out if what you're doing is working. ... I just want to see successes." Stakeholders also expressed interest in continued participation in evaluation in future years.

\section{Limitations and Challenges}

Many of the challenges we faced in the evaluation of T4 and in our collaboration with stakeholders were a function of uncertainty around the commitment to and clarity of collaborative inquiry. As novice evaluators, we struggled to define expectations and structure collaboration in a way that would be optimal for stakeholders and evaluators. As a result, some stakeholders were active participants in meetings throughout the year, while attendance for others was inconsistent. The history and context of the evaluation may also have limited the depth of participation. Familiarity between stakeholders and evaluators built over the first three years of the program was beneficial in soliciting initial buy-in, but this was the first year we had adopted a collaborative approach, requiring more engagement from stakeholders than in previous years. Participation peaked and waned, and it was often difficult to facilitate meaningful collaboration. Literature on collaborative evaluation and the CAE principles made us aware of some of the challenges of collaborative inquiry, but it also cautioned that such inquiry is contingent and rarely follows a script (Cousins \& Chouinard, 2012). As Shulha et al. (2016, p. 203) state, "whether or not evaluators have the wherewithal to mitigate the erosion of commitment to CAE will depend both on the skills of the evaluator and emerging conditions within the organization." The principles were beneficial in surfacing issues and drawing our attention to key dimensions of collaborative inquiry, but success in this type of approach is not achieved by following a prescribed set of directions. What became quite clear to us is that collaborative evaluation requires a blend of theoretical knowledge and practical experience, strong relationships, a receptive organizational culture, and commitment from stakeholders and evaluators. 


\section{CONCLUSION}

Shulha et al. (2016, p. 196) suggest that "the value of [the CAE] principles will rest in their capacity to illuminate complexity rather than resolve it, to inform decisions rather than prescribe them." In utilizing the principles as a guide to collaborative practice, our evaluation team gained a better understanding of the nuances of the program we evaluated and the dynamic nature of soliciting, managing, and integrating stakeholder participation into evaluation practice. The principles also served as a teaching tool for novice evaluators. We gained a better understanding of the potential depth and scope of collaboration with stakeholders and learned through consistent reflection how to shape our evaluation approach to fit the program context. Use of the CAE principles as a guide to practice did not alleviate the ambiguity and uncertainty of collaboration but was beneficial in initiating discussions, clarifying motivations and aims, and encouraging practices that promoted evaluation use.

\section{REFERENCES}

Buckley, J., Archibald, T., Hargraves, M., \& Trochim, W. M. (2015). Defining and teaching evaluative thinking: Insights from research on critical thinking. American Journal of Evaluation, 36(3), 375-388. https://doi.org/10.1177/1098214015581706

Chouinard, J. A., Boyce, A. S., Hicks, J., Jones, J., Long, J., Pitts, R., \& Stockdale, M. (2017). Navigating theory and practice through evaluation fieldwork: Experiences of novice evaluation practitioners. American Journal of Evaluation, 38(4), 493-506. https://doi. org/10.1177/1098214016667582

Chouinard, J. A., Cavanaugh, S. A., Adetogun, A., \& Baker, K. (Forthcoming). A view from the classroom: A reflection on the use of the CAE principles in an instructional setting. In J. B. Cousins (Ed.), Global test drive of principles for collaborative approaches to evaluation (CAE). Thousand Oaks, CA: SAGE.

Cornwall, A., \& Jewkes, R. (1995). What is participatory research? Social Science Medicine, 41(12), 1667-1676. https://doi.org/10.1016/0277-9536(95)00127-s

Cousins, J. B. (Ed.). (Forthcoming). Global test drive of principles for collaborative approaches to evaluation (CAE). Thousand Oaks, CA: SAGE.

Cousins, J. B., \& Chouinard, J. A. (2012). Participatory evaluation up close. Charlotte, NC: Information Age Publishing, Inc.

Cousins, J. B., \& Earl, L. M. (1992). The case for participatory evaluation. Educational Evaluation and Policy Analysis, 14(2), 397-418. https://doi.org/10.2307/1164283

Cousins, J. B., \& Whitmore, E. (1998). Framing participatory evaluation. New Directions for Evaluation, 1998(80), 5-23. https://doi.org/10.1002/ev.1114

Cousins, J. B., Whitmore, E., \& Shulha, L. (2013). Arguments for a common set of principles for collaborative inquiry in evaluation. American Journal of Evaluation, 34(1), 7-22. https://doi.org/10.1177/1098214012464037 
Fetterman, D. M. (2001). Foundations of empowerment evaluation. Thousand Oaks, CA: SAGE.

King, J. A. (2005). Participatory evaluation. In S. Mathison (Ed.), Encyclopedia of evaluation (pp. 292-296). Thousand Oaks, CA: Sage. https://doi.org/10.4135/9781412950558

Mertens, D. M. (2009). Transformative research and evaluation. New York, NY: Guilford Press.

O'Sullivan, R. (Ed.). (2004). Practicing evaluation: A collaborative approach. Thousand Oaks, CA: SAGE.

O'Sullivan, R. (2012). Collaborative Evaluation within a framework of stakeholder-oriented evaluation approaches. Evaluation and Program Planning, 35(4), 518-522. https://doi. org/10.1016/j.evalprogplan.2011.12.005. Medline: 22364849

Patton, M. Q. (2011). Developmental evaluation: Applying complexity concepts to enhance innovation and use. New York, NY: Guilford Press.

Rodríguez-Campos, L. (2005). Collaborative evaluations: A step-by-step model for the evaluator. Tamarac, FL: Llumina Press.

Rodríguez-Campos, L. (2012). Advances in collaborative evaluation. Evaluation and Program Planning, 35(4), 523-528. https://doi.org/10.1016/j.evalprogplan.2011.12.006. Medline: 22377419

Schon, D. (1983). The reflective practitioner: How professionals think in action. New York, NY: Routledge.

Searle, M. J., Merchant, S., Chalas, A., \& Lam, C. Y. (2017). A case study of the guiding principles for collaborative approaches to evaluation in a developmental evaluation context. Canadian Journal of Program Evaluation, 31(3), 350-373. https://doi. org/10.3138/cjpe. 328

Shulha, L. M., Whitmore, E., Cousins, J. B., Gilbert, N., \& al Hudib, H. (2016). Introducing evidence-based principles to guide collaborative approaches to evaluation: Results of an empirical process. American Journal of Evaluation, 37(2), 193-215. https://doi. org/10.1177/1098214015615230

\section{AUTHOR INFORMATION}

Jeremy Acree is a $\mathrm{PhD}$ student in the department of Educational Research Methodology at the University of North Carolina at Greensboro. He works as an evaluator in the university's Office of Assessment, Evaluation, and Research Services. 